\title{
SUBSTITUSI ANTARKONJUNGSI BAHASA JEPANG DALAM NOVEL GUROTESUKU
}

\author{
Dwika Yanti Mnune $^{1}$, I Nyoman Suparwa ${ }^{2}$, Made Sri Satyawati ${ }^{3}$ \\ Mahatma Gandhi-Taman Rama Intercultural School \\ dwikaym@gmail.com ${ }^{1}$, suparwa_nym@yahoo.co.id ${ }^{2}$, srisatyawati@gmail.com ${ }^{3}$ \\ Fakultas Ilmu Budaya, Universitas Udayana ${ }^{2,3}$
}

\begin{abstract}
Abstrak-Penelitian ini bertujuan untuk mengetahui substitusi antarkonjungsi bahasa Jepang yang terdapat dalam suatu wacana. Data yang digunakan dalam penelitian ini adalah data tertulis yang diambil dari wacana novel yang berjudul Gurotesuku karya Natsuo Kirino. Secara umum metode penelitian yang digunakan adalah metode kualitatif. Pengumpulan data dilakukan dengan metode simak dan teknik catat. Sementara itu, digunakan metode informal dalam penyajian hasil analisis data. Teori kohesi dan koherensi yang diusulkan oleh Halliday dan Hasan (1976) serta Halliday (2014) dengan pendekatan struktural dijadikan sebagai teori payung dalam penelitian ini didukung oleh Makino dan Tsutsui (1989 \&1995). Berdasarkan hasil penelitian, diketahui bahwa substitusi antarkonjungsi terjadi pada substitusi internal dan substitusi eksternal. Substitusi internal antarkonjungsi bahasa Jepang yang ditemukan dalam novel Gurotesuku adalah junsetsu no setsuzokushi 'konjungsi hubungan sebab-akibat' yang terdiri atas genin to riyuu 'konjungsi sebab akibat' dan jouken 'konjungsi persyaratan', gyakusetsu no setsuzokushi 'konjungsi pertentangan', iikae to reiji no setsuzokushi 'konjungsi parafrasa', heiretsu to ruika no setsuzokushi 'konjungsi hubungan setara', sentaku no setsuzokushi 'konjungsi pilihan', dan hosoku no setsuzokushi 'konjungsi tambahan'. Pada penelitian ini data menununjukkan bahwa hanya terdapat satu substitusi eksternal antarkonjungsi bahasa Jepang, yaitu heiretsu to ruika no setsuzokushi 'konjungsi hubungan setara' dengan sentaku no setsuzokushi 'konjungsi pilihan' .
\end{abstract}

Kata kunci: substitusi, substitusi internal, substitusi eksternal

Abstract-This study aims to find out the inter-functional substitution of Japanese in a discourse. The data used in this study are written data taken from the discourse of the novel entitled Gurotesuku by Natsuo Kirino. In general, the research method used is a qualitative method. Data collection is done by referring and recording techniques. Meanwhile, informal methods are used in presenting the results of data analysis. The theory of cohesion and coherence proposed by Halliday and Hasan (1976) and Halliday (2014) with a structural approach used as theory in this study is supported by Makino and Tsutsui (1989 \& 1995). Based on the results of the study, it is known that inter-functional substitution occurs in internal substitution and external substitution. The Japanese inter-functional substitution found in Gurotesuku's novel is junsetsu no setsuzokushi 'conjunction cause-effect relationship' which consists of genin to riyuu 'cause and effect conjunctions' and jouken 'conjunction requirements', gyakusetsu no setsuzokushi 'conflict conjunctions', iikae to reiji setsuzokushi no 'parafrasa conjunction', heiretsu to ruika no setsuzokushi 'equivalent relationship conjunction', sentaku no setsuzokushi 'choice conjunction', and hosoku no setsuzokushi 'additional conjunction'. In this study, the data shows that there is only one inter-conjunction external substitution of Japanese, namely heiretsu to ruika no 
LINGUISTIKA, MARET 2019

p-ISSN: 0854-9613

Vol. 26. No. 1

setsuzokushi 'equivalent relationship conjunction' with sentaku no setsuzokushi 'choice conjunction'.

Keywords: substitution, internal substitution, external substitution 


\section{PENDAHULUAN}

Wacana dapat dipahami bukan dalam segi bentuk atau gramatikal, melainkan dalam segi semantik atau makna (Halliday dan Hasan, 1976:2). Dalam arti bahwa dalam penggunaan wacana terdapat tekstur yang memiliki keadaan yang berkait sehingga membentuk suatu yang maujud. Tekstur tersebut dibentuk melalui sebuah ikatan dalam suatu wacana yang disebut dengan kohesi.

Kohesi merupakan suatu komponen yang dihubungkan oleh serangkaian pertalian makna dengan apa yang telah disebutkan sebelumnya (Halliday dan Hasan, 1976:2). Berdasarkan pilihan bentuk yang digunakan, kohesi dapat dibagi menjadi dua bagian, yaitu kohesi gramatikal dan kohesi leksikal. Kohesi leksikal merupakan hubungan antara unsur pembentuk wacana yang secara semantis memanfaatkan unsur kata atau leksikal. Reiterasi dan kolokasi merupakan pembagian kohesi secara leksikal. Kemudian, kohesi gramatikal merupakan hubungan antara unsur yang secara semantis dimarkahi oleh alat-alat gramatikal atau suatu alat kebahasaan yang berkaitan dengan tata bahasa. Adapun pembagian kohesi gramatikal, seperti pengacuan atau referensi, substitusi, pelesapan atau elipsis, dan kata sambung atau konjungsi (Halliday dan Hasan, 1976:4--6). Dalam penelitian ini dibahas lebih lanjut kohesi gramatikal dalam aspek konjungsi.

Konjungsi merupakan bagian dari kohesi yang ditandai dengan adanya relasi antara bagian dalam teks sehingga teks tersebut dapat dipahami. Konjungsi dalam bahasa Jepang disebut dengan setsuzokushi. Setsuzokushi ialah kelas kata yang dipakai untuk menghubungkan atau merangkaikan kalimat dengan kalimat atau merangkaikan bagian-bagian kalimat (Nagayama Isami dalam Sudjianto, 2004:100). Pada bahasa Jepang menurut Iori dan Yamada (2001:462-463) dibagi atas sepuluh jenis. Konjungsi tersebut meliputi junsetsu no setsuzokushi 'konjungsi hubungan sebab-akibat' yang terdiri atas genin to riyuu 'konjungsi sebab-akibat' dan jouken 'konjungsi persyaratan', riyuunobe no setsuzokushi 'konjungsi alasan', gyakusetsu no setsuzokushi 'konjungsi pertentangan', iikae to reiji no setsuzokushi 'konjungsi parafrasa', heiretsu to ruika no setsuzokushi 'konjungsi hubungan setara', hosoku no setsuzokushi 'konjungsi tambahan', sentaku no setsuzokushi 'konjungsi pilihan', taihi no setsuzokushi 'konjungsi perbandingan', tenkan no setsuzokushi 'konjungsi pengalihan topik', dan soukatsu no setsuzokushi 'konjungsi simpulan'. Bahasa Jepang adalah bahasa yang memiliki perbedaan besar dalam hal bahasa tulisan dan bahasa lisan (Wahyuning dkk., 2017:1). Banyaknya konjungsi dengan makna yang sama dalam bahasa tulisan maupun lisan membuat konjungsi-konjungsi tersebut dapat disubtitusikan berdasarkan makna yang sama. Misalnya, konjungsi sore kara dan soshite (Makino dan Tsutsui, 1989:416\&419) yang menyatakan bahwa:

a conjunction that indicates (1) temporally continuous actions or states, or (2) a cumulative listing of objects, actions or states. Soshite and sorekara are interchangeable when two events do not occurs simultaneously. 'Sebuah konjungsi yang menunjukkan (1) tindakan atau kondisi yang terus-menerus secara temporer, atau (2) daftar kumulatif objek, tindakan atau suatu kondisi. Soshite dan sorekara bisa dipertukarkan saat dua kejadian tidak terjadi bersamaan.'

Berdasarkan penjelasan tersebut, konjungsi soshite dan sore kara dapat di substitusikan. Hal tersebut dapat terjadi apabila terdapat dua kejadian atau kegiatan yang terjadi secara tidak bersamaan. Berikut contoh substitusi antarkonjungsi soshite dan sore kara.

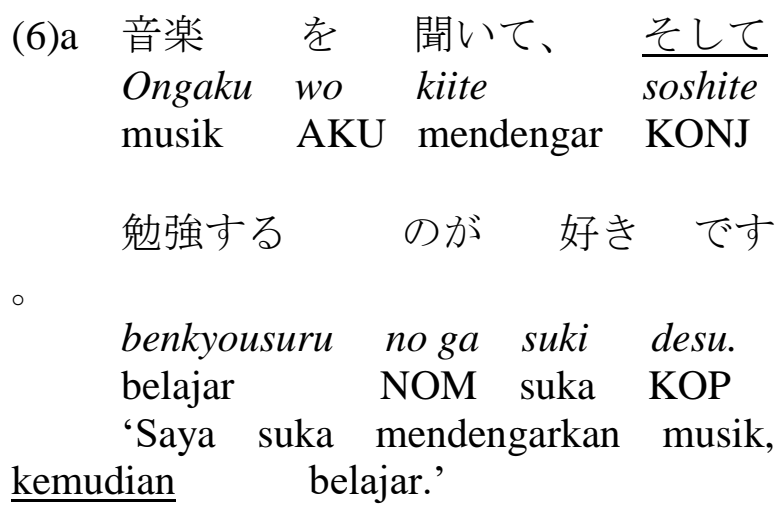

$\begin{array}{lllll}\text { (6)a } & \text { 音楽 } & \text { を } & \text { 聞いて、 } \\ \underline{5} & \text { Ongaku } & \text { wo ko }\end{array}$

sorekara

musik AKU mendengar KONJ 


$\begin{array}{llll}\text { 勉強する } & \text { のが } & \text { 好き } & \text { です } \\ \text { 。 } & & & \\ \text { benkyousuru } & \text { noga } & \text { suki } & \text { desu. } \\ \text { belajar } & \text { NOM } & \text { suka } & \text { KOP }\end{array}$

'Saya suka mendengarkan musik, setelah itu belajar.'

(ADBJG,

1989: 419)

Pada kalimat (6)a dan (6)b terdapat konjungsi soshite 'kemudian' dan konjungsi sorekara 'setelah itu' yang termasuk dalam macam konjungsi yang menyatakan hubungan setara. Dalam hal ini, hubungan setara yang dimaksudkan yaitu hubungan antara klausa satu dan klausa yang ditandai oleh konjungsi merupakan klausa inti yang kedudukannya setara. Contoh tersebut merupakan substitusi yang terjadi pada internal konjungsi hubungan setara. Dalam kedua contoh kalimat tersebut terjadi substitusi antarkonjungsi karena makna yang terkandung dalam kedua kalimat tersebut bisa saling menggantikan apabila kegiatan yang dilakukan tidak terjadi secara bersamaan atau dapat dikatakan memiliki urutan waktu antara kegiatan satu dengan kegiatan lainnya.

Berdasarkan hal tersebut, penting diadakannya penelitian mengenai substitusi antarkonjungsi agar memudahkan pembelajar bahasa khususnya bahasa Jepang untuk memahami penggunaan dari konjungsi-konjungsi tersebut. Belum lagi, belajar bahasa asing seperti bahasa Inggris sebagai bahasa internasional, bahasa Jepang, dan bahasa asing lainnya sangat diperlukan

pada era global seperti sekarang ini (Ernawati, 2018:102). Adapaun masalah yang dibahas dalam penelitian adalah substitusi internal dan eksternal antarkonjungsi bahasa Jepang yang terdapat dalam novel Gurotesuku karya Natsuo Kirino. Data penelitian ini dikaji berdasarkan penerapan teori Halliday dan Hasan (1976) serta Halliday (2014) dengan pendekatan struktural di dukung oleh konsep Makino dan Tsutsui (1989 \&1995).

\section{BAHAN DAN METODE}

Penelitian ini menggunakan data tertulis berupa novel berbahasa Jepang. Novel tersebut berjudul Gurotesuku memiliki tebal halaman 536 halaman yang diterbitkan di Jepang oleh Bungei Shunju LTD pada tanggal 27 Juni 2003. Novel tersebut merupakan novel yang mengangkat kisah enjokousai 'kegiatan berkencan wanita muda dengan pria yang lebih tua'. Penelitian ini merupakan sebuah studi pustaka dengan menjadikan novel Gurotesuku sebagai data penelitian dengan tidak melibatkan data tambahan lainnya. Pengumpulan data menggunakan metode simak dan teknik catat. Data yang disimak, yaitu penggunaan konjungsi bahasa Jepang yang dapat disubstitusikan pada novel Gurotesuku. Dalam hal ini data yang mengandung konjungsi dibagi berdasarkan macam-macamnya dan disubstitusikan berdasarkan makna yang terkandung. Sementara itu, digunakan metode informal dalam penyajian hasil analisis data.

\section{HASIL DAN PEMBAHASAN}

Substitusi antarkonjungsi bahasa Jepang dapat terjadi berdasarkan makna yang terkandung di dalamnya. Substitusi konjungsi bahasa Jepang menggunakan konsep yang dikemukakan oleh Makino dan Tsutsui (1989 dan 1995). Substitusi antarkonjungsi dapat terjadi dalam internal konjungsi maupun eksternal konjungsi.

Substitusi internal antarkonjungsi bahasa Jepang yang ditemukan dalam novel Gurotesuku adalah junsetsu no setsuzokushi 'konjungsi hubungan sebab-akibat', gyakusetsu no setsuzokushi 'konjungsi pertentangan', iikae to reiji no setsuzokushi 'konjungsi parafrasa', heiretsu to ruika no setsuzokushi 'konjungsi hubungan setara', sentaku no setsuzokushi 'konjungsi pilihan', dan hosoku no setsuzokushi 'konjungsi tambahan'. Pada penelitian ini data menununjukkan bahwa hanya terdapat satu substitusi eksternal antarkonjungsi bahasa Jepang, yaitu konjungsi hubungan setara dengan konjungsi pilihan yang ditemukan dalam novel Gurotesuku. Berikut substitusi antarkonjungsi yang terdapat dalam novel Gurotesuku karya Natsuo Kirino. 


\section{- Substitusi Internal}

Substitusi internal konjungsi yang dimaksudkan adalah substitusi yang terjadi dalam cakupan satu kelompok konjungsi saja. Dalam hal ini substitusi terjadi pada junsetsu no setsuzokushi 'konjungsi hubungan sebab-akibat' terdiri atas genin to riyuu 'konjungsi sebab akibat' dan jouken 'konjungsi persyaratan', gyakusetsu no setsuzokushi 'konjungsi pertentangan', iikae to reiji no setsuzokushi 'konjungsi parafrasa', heiretsu to ruika no setsuzokushi 'konjungsi hubungan setara', sentaku no setsuzokushi 'konjungsi pilihan', dan hosoku no setsuzokushi 'konjungsi tambahan'. Berikut substitusi antarkonjungsi bahasa Jepang yang terdapat dalam novel Gurotesuku karya Natsuo Kirino.

\section{- Konjungsi Sebab-Akibat}

Konjungsi sebab-akibat atau junsetsu no setsuzokushi secara mengkhusus dalam bahasa Jepang disebut gen'in to riyuu no setsuzokushi terbagi atas dakara, sore de, sono tame (ni), soko de, sono kekka, shitagatte, yueni, dan sore yueni. Kemudian, konjungsi persyaratan yang berkaitan dengan hubungan sebab-akibat dalam bahasa Jepang dikatakan jouken no setsuzokushi terdiri atas suru to, sore nara, dattara, sore dewa, sore ja, dewa, dan ja. Dalam menyatakan hubungan sebab-akibat, penelitian ini menemukan lima konjungsi yang tergolong gen'in to riyuu no setsuzokushi dan dapat disubstitusikan. Kelima konjungsi tersebut ialah konjungsi dakara, sore de, shitagatte, soko de, dan yue ni. Substitusi antarkonjungsi sebab-akibat tersebut meliputi konjungsi sore de dengan dakara, shitagatte dengan dakara, dan soko de dengan sore de. Berikut substitusi antarkonjungsi sebab-akibat yang diwakili oleh konjungsi sore de dengan dakara.

Sore de merupakan konjungsi yang menunjukkan apa yang dinyatakan dalam kalimat sebelumnya adalah alasan atau penyebab dari apa yang dinyatakan dalam kalimat berikut (Makino dan Tsutsui, 1989:413). Dalam penggunaannya, konjungsi sore de dapat saling menggantikan dengan konjungsi dakara. Makino dan Tsutsui (1989:414) menyatakan bahwa sore de dapat saling menggantikan dengan konjungsi dakara apabila keduanya menyatakan sebab atau alasan.
Berikut data substitusi antarkonjungsi sore de dengan dakara.

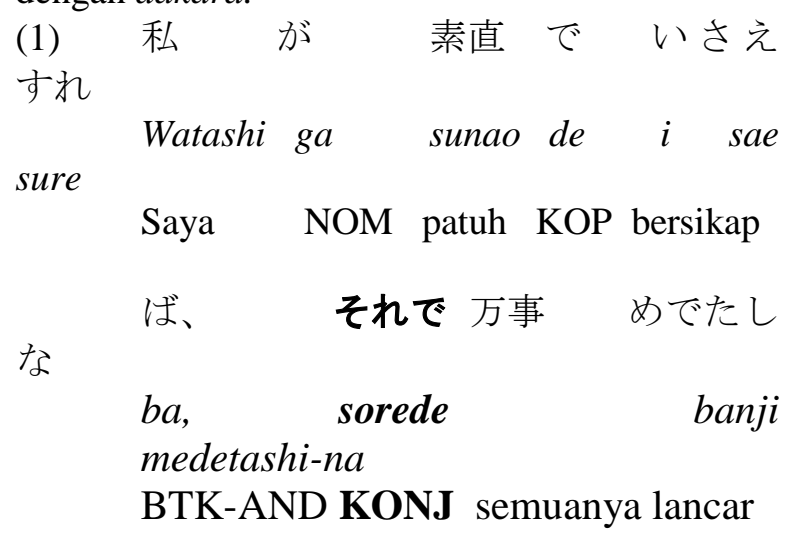

のだった。(Guro, 165)

no datta.

\section{JOD-LAM}

'Yang perlu kulakukan hanya bersikap patuh dan semuanya berjalan lancar.' (Grotes, 178)

Pada data (1) konjungsi dakara dengan sore de dapat saling menggantikan dalam menyatakan sebab atau alasan yang terdapat dalam suatu konteks kalimat. Sebab atau alasan yang terdapat dalam data (1) menyatakan tokoh Aku, yaitu Yuriko bersikap patuh dengan mengikuti apa yang dilakukan oleh Masami sebagai lawan bicaranya dengan alasan bahwa semuanya akan berjalan lancar apabila ia mau menurutinya.

\section{- Konjungsi Hubungan Setara}

Konjungsi hubungan setara atau heiretsu to ruika no setsuzokushi dalam bahasa Jepang terdiri atas soshite, sorekara, sore ni, mata, sono ue, shikamo, sara ni, mata, omake ni, sore bakari denaku, oyobi, narabini, sore bakari ka, nomi narazu, sore dokoroka, dan katsu (Iori dan Yamada, 2001:462). Penelitian ini hanya menemukan tiga konjungsi yang dapat disubstitusikan. Ketiga konjungsi tersebut adalah konjungsi sorekara, soshite, dan katsu. Subsitusi antarkonjungsi hubungan setara meliputi konjungsi sorekara dengan soshite dan katsu dengan soshite. Berikut substitusi antarkonjungsi hubungan setara yang diwakili oleh konjungsi katsu dengan soshite. 
Katsu dapat saling menggantikan dengan soshite apabila keduanya menjelaskan milik atau tingkah laku seseorang atau benda (Makino dan Tsutsui, 1995:213). Berikut data substitusi antarkonjungsi katsu dengan soshite yang terdapat dalam novel Gurotesuku.

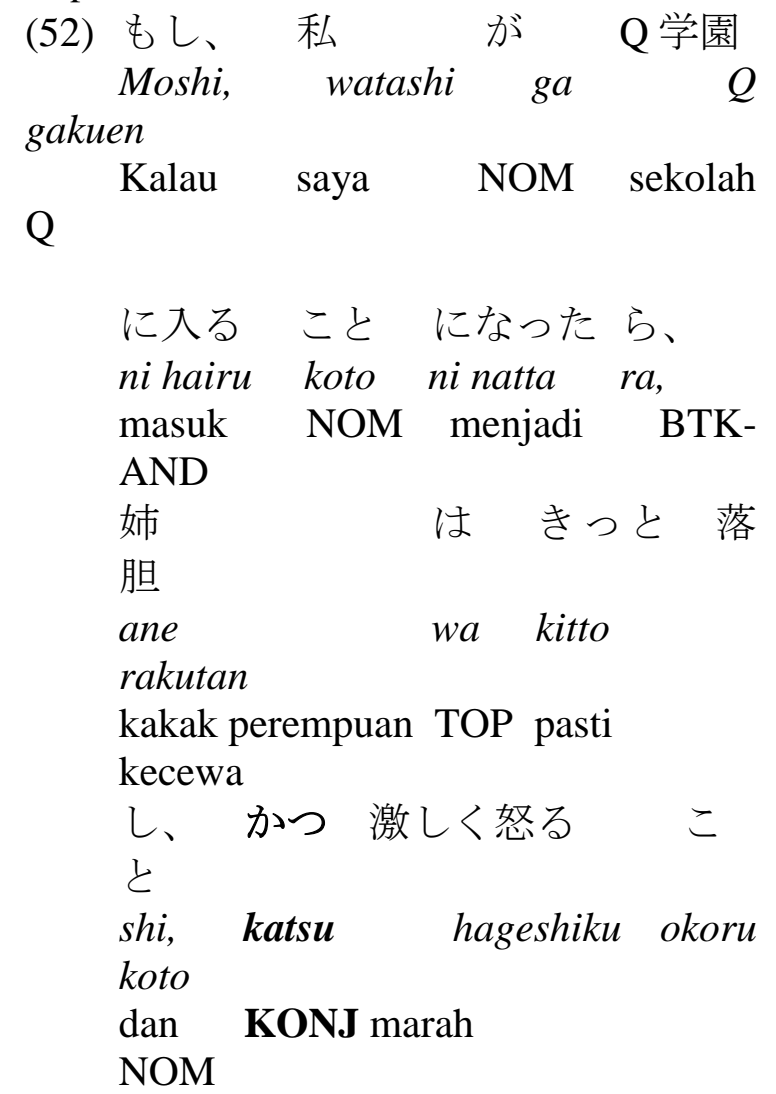

だろう。(Guro, 154)

darou.

KOP

'Kalau aku masuk sekolah Q, itu pasti akan membuatnya tertekan.' (Grotes, 175)

Konjungsi katsu dalam data (52) dapat disubstitusikan dengan konjungsi soshite karena kedua konjungsi tersebut menggambarkan situasi atau kondisi sifat orang pada saat yang sama secara berurutan. Dalam hal ini Yuriko menggambarkan situasi yang terjadi seandainya ia masuk sekolah yang sama dengan kakaknya. Ia juga menggambarkan bagaimana kondisi tertekan kakaknya apabila ia bertemu di sekolah yang sama. Apalagi kakaknya sudah berjuang keras untuk dapat masuk sekolah $\mathrm{Q}$, hanya untuk melarikan diri darinya.

\section{- Konjungsi Pertentangan}

Konjungsi pertentangan atau gyakusetsu no setsuzokushi merupakan konjungsi yang menyatakan hubungan pertentangan atau kontrastif. Konjungsi ini terdiri atas keredomo, dakedo, ga, demo, shikashi nagara, sore nanoni, nanoni, ni mo kakawarazu, tokoro ga, sore ga, to wa ie, dan to wa iu mono no (Iori dan Yamada, 2001:462). Pada penelitian ini hanya ditemukan konjungsi keredomo, dakedo, ga, tokoro ga, dan sore ga yang dapat disubstitusikan satu sama lainnya. Berikut substitusi antarkonjungsi pertentangan yang diwakili konjungsi $g a$ dengan dakedo dan keredomo.

$\mathrm{Ga}$ merupakan konjungsi yang digunakan dalam menghubungkan dua kalimat yang mengekspresikan ide pertentangan (Makino dan Tsutsui, 1989:122). Konjungsi ini juga dapat saling disubstitusikan dengan konjungsi dakedo dan keredomo apabila menyatakan suatu ide yang sama, yaitu mengenai suatu pertentangan.

\begin{tabular}{|c|c|c|}
\hline Watashi & $w a$ & hitori \\
\hline $\begin{array}{l}\text { Masami } \\
\text { Saya }\end{array}$ & TOP & sendiri \\
\hline
\end{tabular}

の作った弁当を食べた

no tsukuttabentou wo tabeta.

GEN bekal makanan AKU makan yang dibuat

$\begin{array}{ccc}\text { が、 } & \text { 食べても } & \text { 食べて } \\ \text { も } & & \\ \begin{array}{c}\text { Ga, } \\ \text { mo }\end{array} & \text { tabete mo } & \text { tabete } \\ \begin{array}{c}\text { KONJ } \\ \text { pun }\end{array} & \text { walau makan } & \text { makan }\end{array}$

$\begin{array}{lll}\text { 弁当 } & \text { は } & \text { なく } \\ \text { bentou } & w a & n a k u \\ \text { bekal makanan } & \text { TOP } & \text { habis }\end{array}$

ならなかった。(Guro, 167) 
Vol. 26. No. 1

naranakatta.

tidak pernah

'Aku duduk sendirian dan makan makan siang yang sudah disiapkan Masami untukku. Tetapi walau seberapa pun aku makan, makan siangnya seperti tidak pernah habis.' (Grotes, 182)

Data (75) menjelaskan bahwa konjungsi ga dengan keredomo menyatakan suatu hal yang bertentangan dalam kasus selanjutnya dan kasus sebelumnya. Dalam hal ini Yuriko yang duduk sendirian sedang menghabiskan makan siang yang dibuat oleh Masami. Namun, makan siang yang dimakan oleh Yuriko tersebut tidak habis juga meskipun dipaksakan untuk memakannya.

\section{- Konjungsi Pilihan}

Konjungsi pilihan atau sentaku no setsuzokushi merupakan konjungsi yang menghubungkan dua pilihan atau lebih dalam suatu kalimat. Konjungsi pilihan menurut Iori dan Yamada (2001:462) terbagi atas mata wa, soretomo, aruiwa, naishiwa, dan moshikuwa. Kelima konjungsi tersebut dapat saling disubstitusikan berdasarkan konteks yang terdapat dalam wacana. Penelitian ini hanya menemukan data konjungsi soretomo dan aruiwa yang dapat disubstitusikan.

Aruiwa merupakan konjungsi yang digunakan dalam menandai pilihan atau kemungkinan bergantung pada strukturnya (Makino dan Tsutsui, 1995:20). Konjungsi aruiwa dapat saling menggantikan dengan konjungsi soretomo apabila pembicara ingin mengetahui pilihan mana yang akan dipilih oleh lawan bicara. Berikut data substitusi antarkonjungsi tersebut.

(81) 上手に 出来なかった 混ぜご 飯

\begin{tabular}{|c|c|c|}
\hline $\begin{array}{l}\text { Jouzu ni } \\
\text { gohan }\end{array}$ & dekinakatta & \\
\hline $\begin{array}{l}\text { Pandai } \\
\text { campur }\end{array}$ & tidak dibuat & \\
\hline とか、 & 納豆 & 値 \\
\hline
\end{tabular}

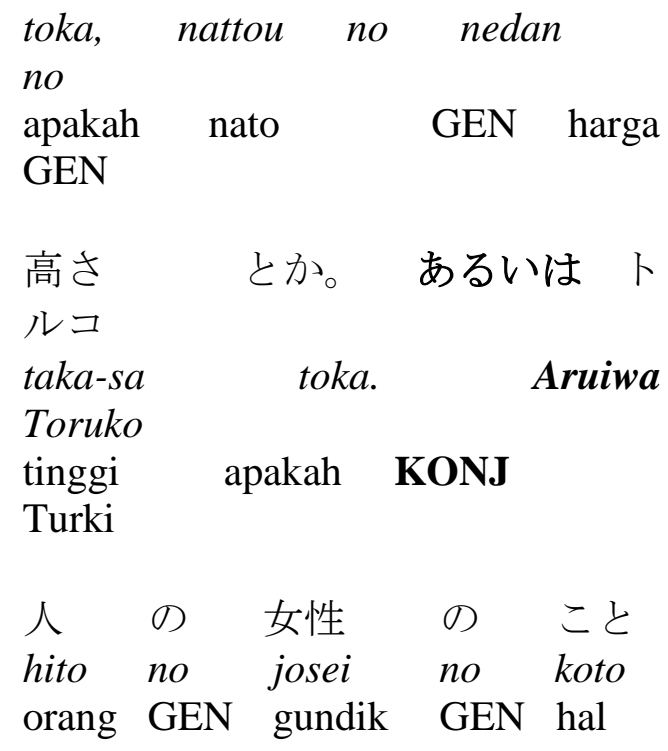

とか、カールと私の toka, kaaru to watashi no apakah Karl dan saya GEN

情事 とか。(Guro, 144)

jyouji toka.

selingkuh apakah

'Apakah nasi yang tidak dimasak dengan baik kemarin? Harga tinggi natto, kedelai fermentasi? Atau gundik Turki ayahku? Mungkin perselingkuhanku dengan Karl?' (Grotes, 161)

Konjungsi aruiwa pada data (81) dapat saling menggantikan dengan soretomo dalam menyatakan keingintahuan pembicara mengenai pilihan mana yang akan dipilih oleh lawan bicara. Dalam hal ini Yuriko sebagai pembicara bertanya-tanya dan masih bingung mengenai masalah apa yang terjadi pada ibunya sehingga ibunya sampai bunuh diri. Ia bertanya-tanya mengenai hal tersebut dengan beberapa pilihan, seperti ibunya yang tidak memasak nasi dengan baik, harga nato atau kedelai fermentasi yang mahal, istri siri suaminya, atau perselingkuhan Yuriko dengan Karl. Hal tersebut selalu terbayang-bayang dalam pikiran Yuriko dan ia berharap ibunya akan menjawab salah satu dari pilihan yang diberikan Yuriko tersebut. Namun, hal tersebut sudah terlambat baginya karena 
ibunya sudah meninggal bunuh diri dengan alasan yang tidak diketahui oleh pihak keluarga.

\section{- Konjungsi Tambahan}

Konjungsi tambahan atau hosoku no setsuzokushi merupakan konjungsi yang menyatakan penambahan hal atau informasi dalam suatu wacana. Konjungsi ini terbagi atas nao, tada, tadashi, mottomo, dan chinamini (Iori dan Yamada, 2001:462). Penelitian ini hanya menemukan konjungsi nao, tada, dan tadashi yang dapat disubstitusikan. Substitusi antarkonjungsi tersebut meliputi konjungsi nao dengan tada dan tadashi dengan tada. Berikut substitusi antarkonjungsi tambahan yang diwakili konjungsi nao dengan tada.

Konjungsi nao dapat saling disubstitusikan dengan konjungsi tada apabila keduanya menyatakan penambahan informasi (Makino dan Tsutsui, 1995:347). Berikut data substitusi antarkonjungsi tada dengan nao yang terdapat dalam novel Gurotesuku.

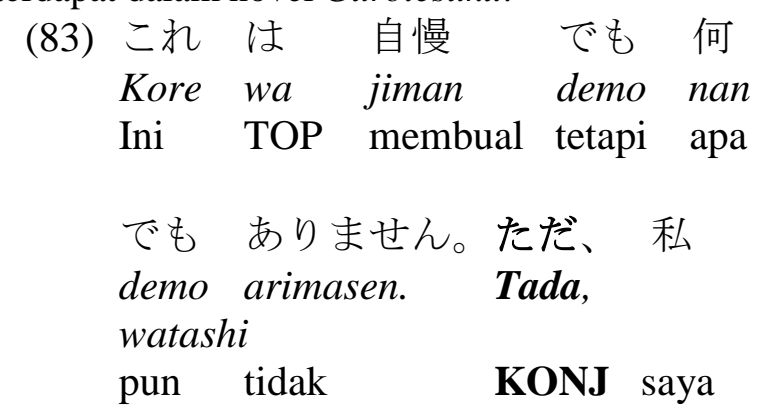

の 状況 を 知っていただ
きたく
no joukyou wo shitte
itadakitaku,
GEN kondisi AKU memahami

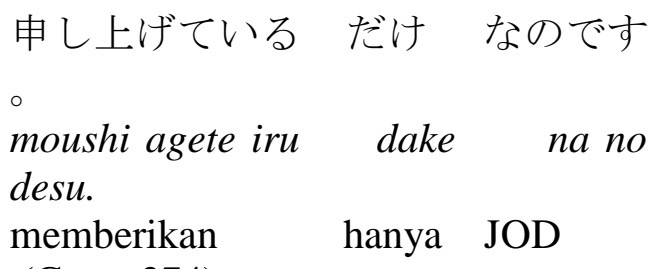

(Guro, 274)

'Saya tidak menulis ini untuk membual, tetapi agar yakin bahwa
Anda memahami kondisi pada masa saya dibesarkan.' (Grotes, 310--311)

Konjungsi tada pada data (83) menyatakan penambahan informasi dan dapat saling menggantikan dengan konjungsi nao. Dalam hal ini terdapat suatu pernyataan yang disampaikan oleh orang tua serta saudarasaudara Zhang saat ia masih kecil bahwa Zhang merupakan anak yang paling cerdas di antara teman-temannya. Zhang menambahkan bahwa hal yang disebutkan sebelumnya tidak untuk membual, tetapi agar dapat dipahami bagaimana kondisi saat ia dibesarkan. Pada kalimat selanjutnya, Zhang menambahkan informasi mengenai dirinya bahwa ia berhasil membaca dan menulis dengan waktu teramat singkat.

\section{- Konjungsi Parafrasa}

Iikae to reiji no setsuzokushi 'konjungsi parafrasa' merupakan konjungsi yang digunakan dalam mengungkapkan kembali suatu pernyataan tanpa mengubah maknanya. Konjungsi ini terdiri atas tsumari, sunawachi, you suru ni, tatoeba, dan iwaba (Iori dan Yamada, 2001:462). Penelitian ini hanya menemukan substitusi antarkonjungsi tsumari dengan you suru ni.

Tsumari dan you suru ni dapat saling menggantikan ketika pernyataan pertama dan pernyataan kedua berupa kalimat bukan nomina atau frasa nominal (Makino dan Tsutsui, 1995:542). Berikut substitusi antarkonjungsi tsumari dan you suru ni yang terdapat dalam novel Gurotesuku.

$$
\begin{array}{lll}
\text { 「あなた } & \text { の } & \text { 家 } \\
\text { つて } & & \\
\text { “Anata } & \text { no } & \text { ie } \\
\text { tte } & & \\
\text { Kamu } & \text { GEN } & \text { keluarga } \\
\text { PART } & &
\end{array}
$$$$
\text { サラリーマン なの? }
$$

まり、

sarariman na no?

Tsumari,

pegawai bayaran bukan?

KONJ 
Vol. 26. No. 1

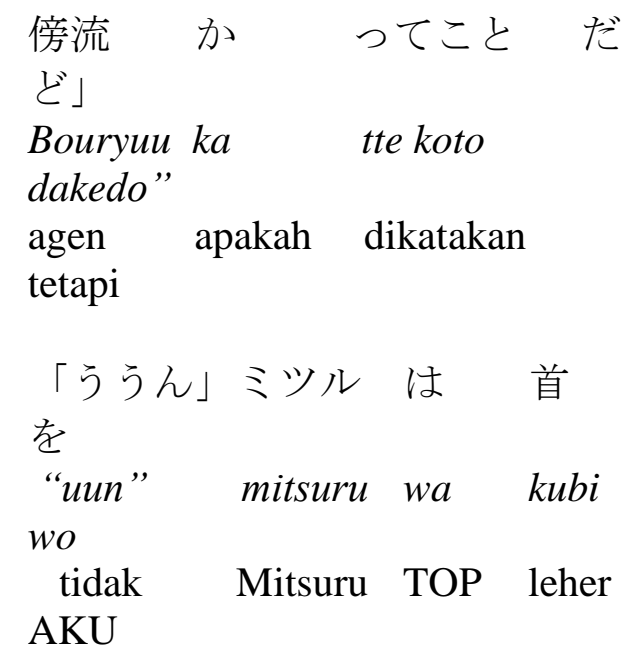

振りました。(Guro, 75)

furimashita.

mengayunkan

'Ayahmu pegawai bayaran?

Maksudku, apakah kau salah satu dari para pengorbit?" "Ya," Mitsuru mengangguk.' (Grotes, 80)

Tsumari pada data (86) dapat saling menggantikan dengan you suru ni karena pernyataan pertama dan pernyataan kedua berupa kalimat bukan nomina atau frasa nominal. Hal tersebut terlihat pada pernyataan pertama yaitu, Anata no ie tte sarariiman na no? Pernyataan kedua yaitu bouryuu ka tte koto dakedo 'apakah kau salah satu dari para pengorbit?' pernyataan ini merupakan kalimat bukan nomina atau frasa nominal.

\section{- Substistusi Eksternal}

Substitusi eksternal antarkonjungsi terjadi pada beberapa macam konjungsi yang berbeda. Eksternal yang dimaksudkan, yaitu di luar bagian yang tergolong dalam satu kelompok. Pada penelitian ini substitusi antarkonjungsi terdapat pada heiretsu to ruika no setsuzokushi 'konjungsi hubungan setara', yaitu mata dengan sentaku no setsuzokushi 'konjungsi pilihan', yaitu aruiwa.

Mata dapat saling menggantikan dengan konjungsi aruiwa apabila keduanya menyatakan pilihan lain dalam suatu konteks kalimat. Berikut data substitusi yang terdapat dalam novel Gurotesuku.

$\begin{array}{llll}\text { (88) 手紙 } & \text { は、 } & \text { 何か } & \text { あった } \\ \text { Tegami } & \text { wa, } & \text { nani ka } & \text { atta } \\ \text { Asuransi } & \text { TOP } & \text { sesuatu } & \text { ada }\end{array}$

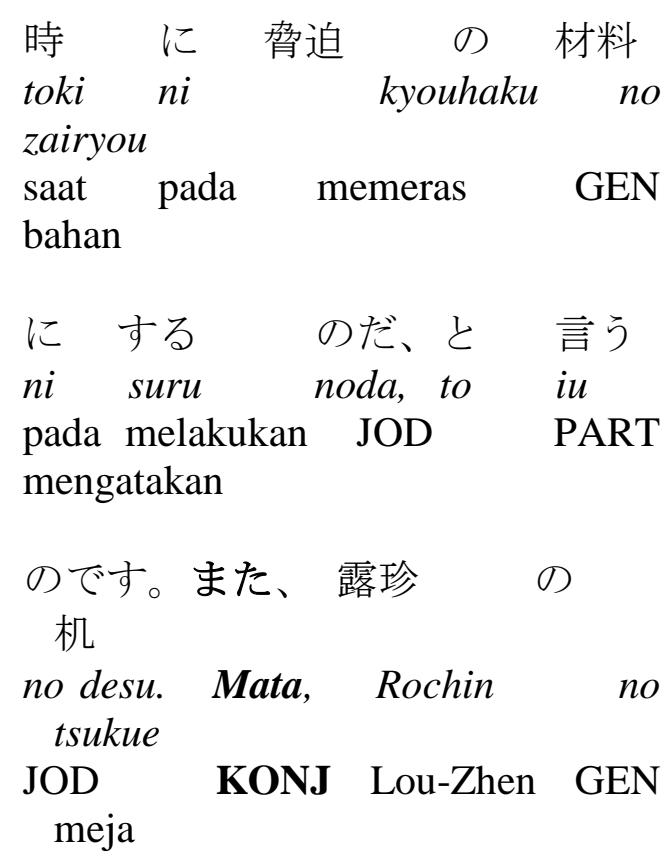

$\begin{array}{llll}\text { の } & \text { 引出し } & \text { を } & \text { 開け } \\ \text { て } & & & \\ \text { no } & \text { hikidashi } & \text { wo } & \text { akete } \\ \text { GEN } & \text { membongkar } & \text { AKU } & \text { buka } \\ & & & \\ \text { 金庫 } & \text { の } & \text { 鍵 } & \text { を } \\ \text { kinko } & \text { no } & \text { kagi } & \text { wo } \\ \text { peti uang } & \text { GEN } & \text { kunci } & \text { AKU }\end{array}$

探したりしていました。(Guro, 321)

sagashitari shite imashita.

mencari

'Katanya ia akan menyimpannya sebagai asuransi, seandainya suatu waktu ia terpaksa memeras LouZhen. Ia juga membongkar laci-laci meja Lou-zhen, mencari-cari kunci peti uangnya.' (Grotes, 368)

Konjungsi mata pada data (88) menyatakan pilihan lain yang terdapat dalam suatu 
konteks kalimat. Konjungsi ini dapat disubstitusikan dengan konjungsi aruiwa karena menyatakan hal yang sama. Dalam hal ini $\mathrm{Yu}$ Wei yang mengobrak-abrik keranjang sampah kemudian mengambil konsep surat yang dibuang Lou-zhen sebagai asuransi ketika diperas oleh Lou-Zhen suatu saat. Selain itu, terdapat pilihan lainnya jika suatu waktu diperas oleh Lou-Zhen, Yu Wei membongkar laci meja dan mencari kunci peti uang milik Lou-Zhen.

\section{SIMPULAN}

Berdasarkan analisis yang telah dilakukan, simpulan dalam penelitian mengenai substitusi antarkonjungsi bahasa Jepang dalam novel Gurotesuku adalah pada substitusi internal, konjungsi sore de pada hubungan sebab-akibat dapat saling disubstitusikan dengan konjungsi dakara dan soko de, serta konjungsi dakara dengan sore de dan shitagatte. Pada konjungsi hubungan setara, konjungsi soshite dapat disubstitusikan dengan konjungsi sorekara dan katsu. Konjungsi pertentangan tokoro ga dapat saling disubstitusikan dengan konjungsi sore ga dan keredomo, keredomo dengan tokoro ga dan $g a$, serta ga dengan keredomo dan dakedo. Kemudian, konjungsi pilihan soretomo dapat saling menggantikan dengan konjungsi aruiwa. Konjungsi tambahan tada dapat saling disubstitusikan dengan konjungsi nao dan tadashi. Terakhir, konjungsi parafrasa tsumari dapat saling menggantikan dengan konjungsi you suru ni. Selain itu, pada substitusi eksternal, konjungsi hubungan setara mata dapat saling menggantikan dengan konjungsi pilihan aruiwa.

\section{PUSTAKA PUSTAKA}

Ernawati, Ni Luh. Campur Kode Bahasa Jepang oleh Penutur Bahasa Indonesia di Jejaring Sosial Facebook. Linguistika: Buletin Ilmiah Proram Magister Linguistik Universitas Udayana, [S.1.], v. 49, n. 25, p. 101-111, sep. 2018. ISSN 0854-9613.

Halliday, M.A.K. dan Ruqaiya, Hassan. 1976. Cohesion In English. Singapura: Longman Singapore.
Halliday, M.A.K. 1985. An Introduction to Functional Grammar. Great Britain: Edward Arnold.

Halliday, M.A.K dan Matthiessen. 2014. Halliday's Introductional to Functional Grammar-Fourth Edition. USA dan Kanada: Routledge.

Iori, Yamada et al. 2001. Shokyuu wo Oshieru Hito no Tame no Nihongo Bunpou Hando Bukku. Tokyo: 3A Corporation.

Kirino, Natsuo. 2003. Gurotesuku. Japan: Bungei Shunjuu.

Kirino, Natsuo. 2010. Grotesque. Diterjemahan oleh Gita Yuliani. Jakarta: PT Gramedia Pustaka Utama.

Seiichi, Makino dan Tsutsui, Michio. 1995. A Dictionary of Intermediate Japanese Grammar. Japan: The Japan Times.

Seiichi, Makino dan Tsutsui, Michio. 1989. A Dictionary of Basic Japanese Grammar. Japan: The Japan Times.

Seiichi, Makino dan Tsutsui, Michio. 1989. A Dictionary of Advanced Japanese Grammar. Japan: The Japan Times. Sudjianto. 2004. Gramatika Bahasa Jepang Modern, Seri A. Bekasi: Kesaint Blanc.

Wahyuningtias, Hani; Artadi, Ari; Dyaya, Hermansyah. Partikel Akhir Kalimat bahasa Jepang Dan Bahasa Indonesia. Linguistika: Buletin Ilmiah Proram Magister Linguistik Universitas Udayana, [S.1.], v. 24, n. 46 , p. $1-14$, mar. 2017. ISSN 0854-9613 